\title{
Fractures of the terminal phalanx presenting as a paronychia
}

H. R. GULY

Department of Accident and Emergency Medicine, Derriford Hospital, Plymouth, Devon

\section{SUMMARY}

Three fractures at the base of the terminal phalanx of the finger and one at the base of the terminal phalanx of the toe were initially misdiagnosed as paronychias. If a 'paronychia' follows trauma, the possibility of a fracture should be considered and radiographs taken of the digit.

\section{INTRODUCTION}

Accident and emergency (A\&E) departments often treat patients with soft tissue infections, one of the commonest of which is a paronychia. This paper describes four patients with fractures of the terminal phalanx who were initially misdiagnosed as having a paronychia.

\section{CASE REPORT 1}

A 12-year-old boy attended the A\&E department 10 days after injuring his middle finger. The nail had been displaced from the proximal nail fold but had been replaced. Five days later the nail fold was said to have been infected and his general practitioner (GP) had prescribed amoxycillin.

On examination he was thought to have a paronychia and a ruptured extensor tendon. Under a digital nerve block the nail was removed. The finger was dressed and immobilized in a mallet splint.

At review 3 days later there was no evidence of infection but an epiphyseal fracture was suspected clinically and a radiograph (Fig. 1) confirmed a fracture which required manipulation. 


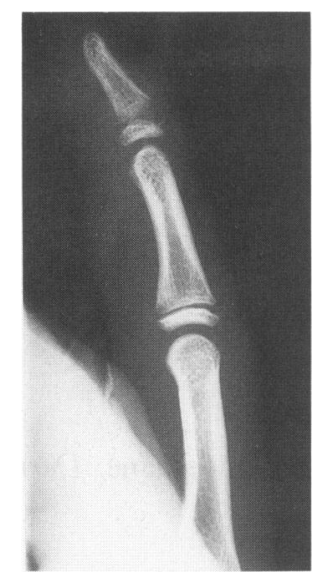

Fig. 1. Radiograph demonstrating fracture.

\section{CASE REPORT 2}

An 11-year-old girl attended the A\&E department with a painful middle finger. $N^{\circ} \stackrel{\circ}{\square}$ proper history was obtained but on examination she was said to have an ear $\overrightarrow{8} \dot{0}$ paronychia. Fusidic acid ointment was prescribed.

At review 2 days later there was no evidence of sepsis but an epiphyse fracture was suspected. A radiograph confirmed a minimally displaced epiphyseal fracture of the terminal phalanx which required no treatment.

\section{CASE REPORT 3}

A 14-year-old girl attended the A\&E department 10 days after knocking her little finger. The day before her attendance it had become more painful.

On examination there was redness at the base of the nail and an early paronychia $\stackrel{3}{3}$. was diagnosed. She was started on a course of amoxycillin and clavulanic acid $\stackrel{\rho}{\S}$ ('Augmentin') and was discharged.

She re-attended 6 days later as the finger was still red. On examination she had 9 a mallet deformity. A radiograph showed an avulsion fracture at the base of the $\frac{\overrightarrow{ }}{\mathrm{a}}$ terminal phalanx (Fig. 2).

\section{CASE REPORT 4}

A 7-year-old boy attended the A\&E department after stubbing his big toe. He had $\stackrel{\oplus}{+}$ swelling and bruising with a small laceration at the base of the nail. A radiograph $\frac{0}{0}$ 


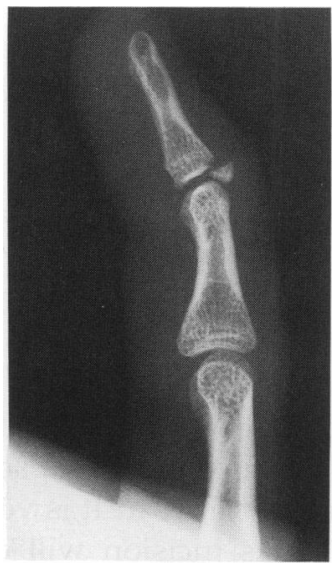

Fig. 2. Radiograph showing avulsion fracture at the base of the terminal phalanx.
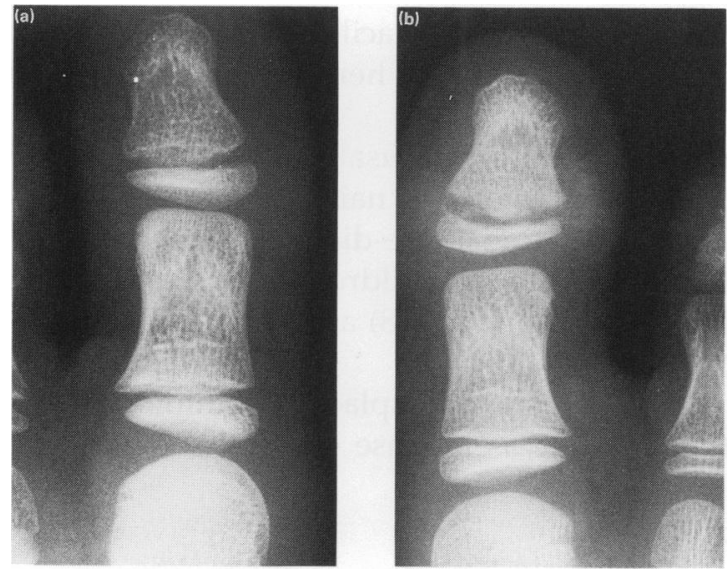

Fig. 3. (a) Initial radiograph of case 4 which was thought to be normal. (b) Second radiograph taken on re-attendance, also thought to be normal. In retrospect it was acknowledged that both showed epiphyseal fracture.

(Fig. 3a) was thought to be normal and was reported as such. He was discharged. Twelve days later he reattended after stubbing his toe again. The toe was red and swollen and he was started on amoxycillin and clavulanic acid ('augmentin').

Four days later he attended again. On examination he was said to have a paronychia and this was incized under local anaesthetic but no pus was found. A further radiograph (Fig. $3 b$ ) was thought by a junior doctor to be normal and the patient was again discharged.

The radiograph was later reported as showing a healing epiphyseal fracture and in retrospect it was acknowledged that the first radiograph had also shown a fracture. 


\section{DISCUSSION}

The epiphysis of the terminal phalanx is situated just proximal to the base of the nail. A fracture at this site will cause swelling and tenderness and this, together with redness and warmth due to the inflammatory response which is part of the healing process may mimic an infection. It is not impossible for an infection to coexist with epiphyseal fractures as the overlying skin is very thin and these fractures may be compound. This is not always apparent and osteomyelitis can result (Yellin et al., 1985). However when these patients were seen at a later date, there was no evidence of sepsis.

Most acute paronychias which present to A\&E departments have pus present and standard treatments include incision if the abscess is confined to the nailfold or removal of the nail if pus extends under it. It is very important that fractures are not misdiagnosed as paronychias as incision will convert a closed injury into a compound fracture. It is equally important not to remove the nail as this acts as a splint for the fracture and if it is removed any reduction becomes unstable and the position of the fracture may slip (Seymour, 1966).

Most acute paronychias are staphylococcal infections and if antibiotics are required, the drug of choice is flucloxacillin. The antibiotics given, in and out of hospital, to the patients described here would not be considered standard treatment.

In an early paronychia the infection usally confined to one side of the nail. To have inflammation at the base of the nail and on both sides but without pus would be unusual and should cause the diagnosis to be reconsidered. Epiphyseal fractures should also be suspected in children in whom the nail has been displaced from the nail bed (Engber \& Clancy 1978) as in Case 1 or in children with a mallet deformity.

The radiological features of an undisplaced or minimally displaced epiphyseal fracture may be difficult to see as in Case 4.

\section{CONCLUSION}

Fractures at the base of the terminal phalanx may be misdiagnosed as paronychias by the inexperienced. An accurate history should always be obtained and if a patient with a paronychia gives a history of trauma, a fracture should be suspected and the digit radiographed. In a child, the subtle appearances of an epiphyseal fracture should be looked for.

\section{REFERENCES}

Engber W. D. \& Clancy W. G. (1978) Traumatic avulsion of the finger nail associated with injury to the phalangeal epiphyseal plate. Journal of Bone and Joint Surgery 60A, 713-714. 
Seymour N. (1966) Juxta-epiphyseal fracture of the terminal phalanx. Journal of Bone and Joint Surgery 48B 347-349.

Yellin J. A., Towbin R. B. \& Kaufman R. A. (1985) Stubbed finger osteomyelitis. Journal of Trauma 25, 808-809. 